\title{
PLANTS BRAVELY FIGHTING METALS
}

Merely a dozen years ago, Silesia was the most powerful industrial center in Poland. Despite the fact that the emission of harmful substances into the environment has been reduced as the number of polluting plants has been diminished and the obligation to use appropriate filters has been introduced, the region still has to cope with the residues of heavy metals which remain in the soil, water, mining waste dumps, and in the air. Metals will not disappear on their own; they are absorbed by plants which, in turn, animals feed on, and these animals pass their "uninvited occupants" to each other. As a result, metals pose a threat to humans as well. Uncovered post-mining and post-manufacturing landfills around which housings are erected carry significant amounts of toxic dust which finds its way into human bodies. However, it turns out that there are plant species which attach themselves to contaminated areas and only occur where heavy metal concentrations are high.
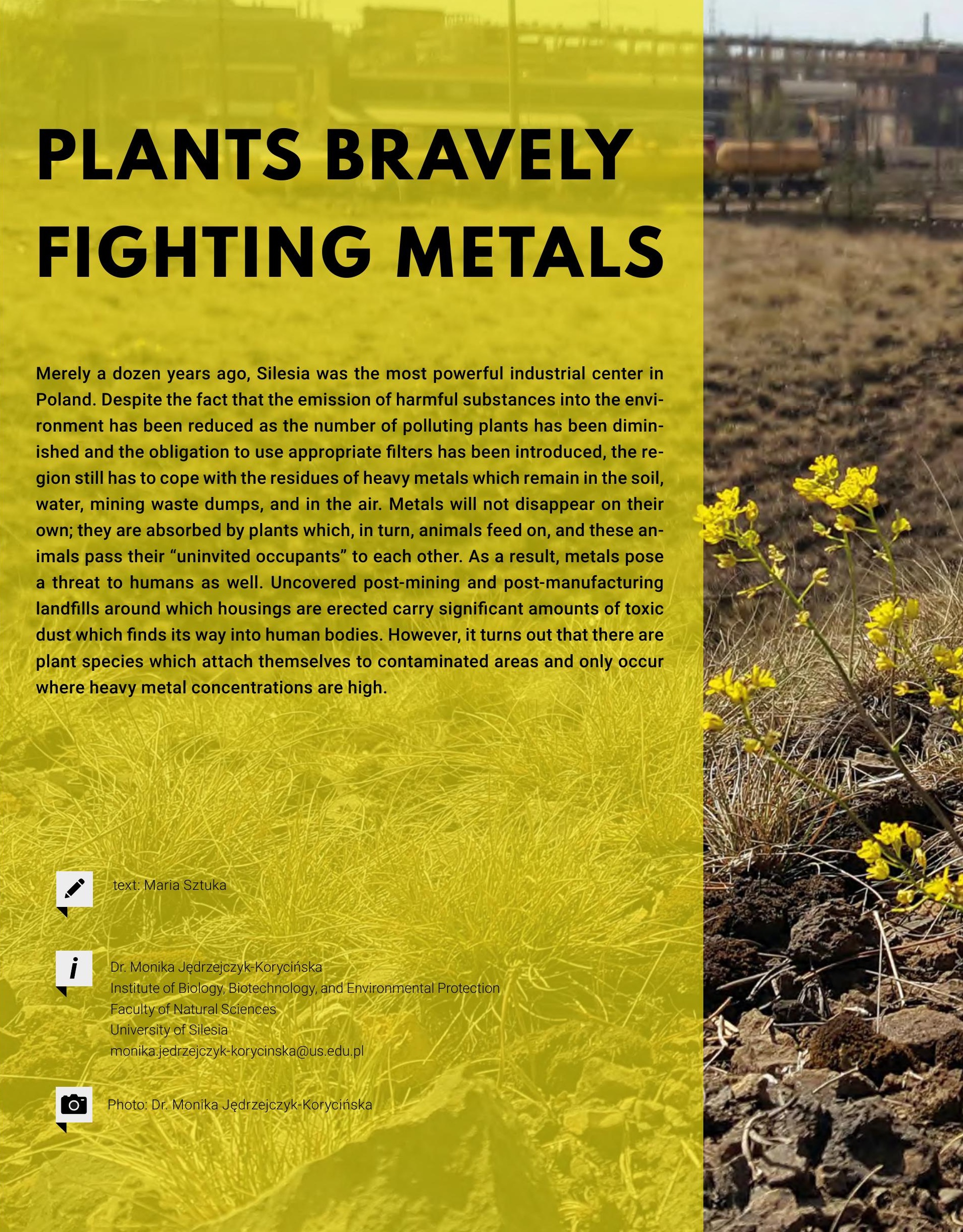


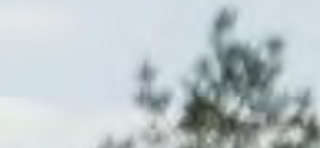 \\ 50 totow}

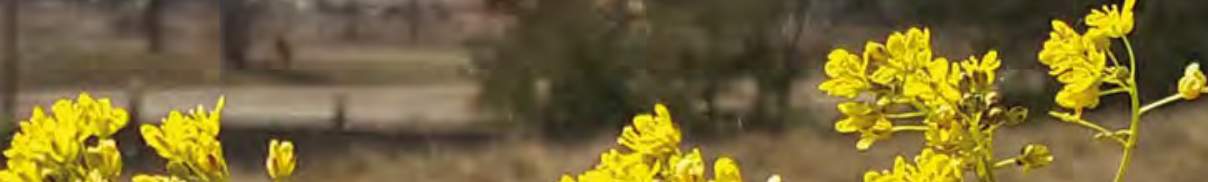
ats.

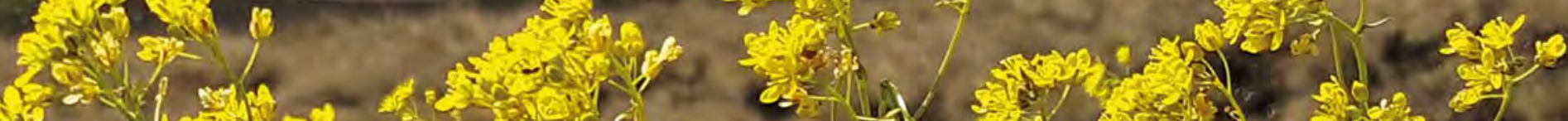
20

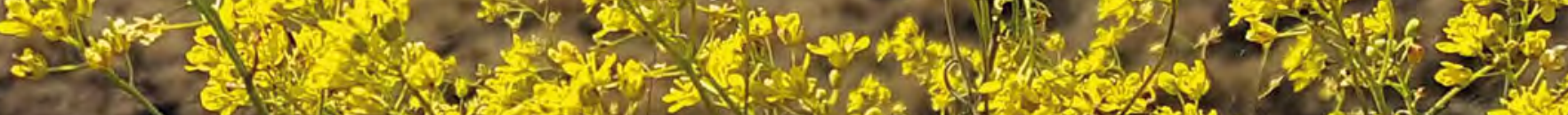

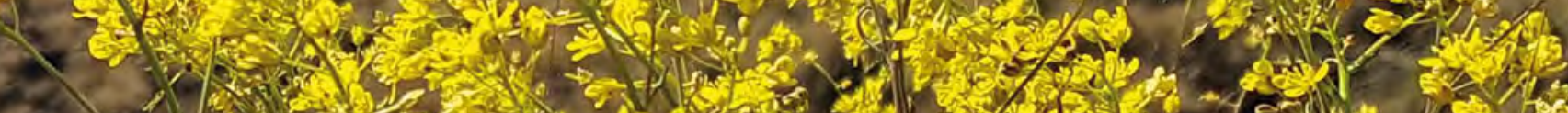
3.

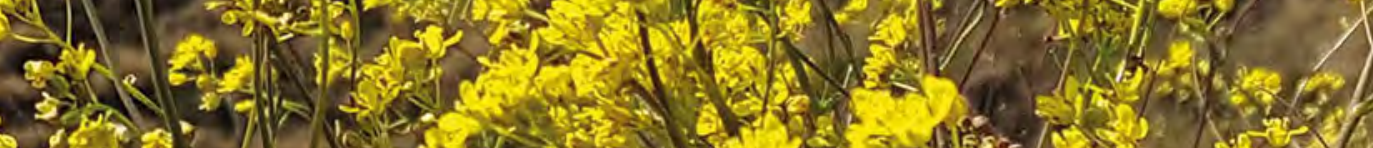

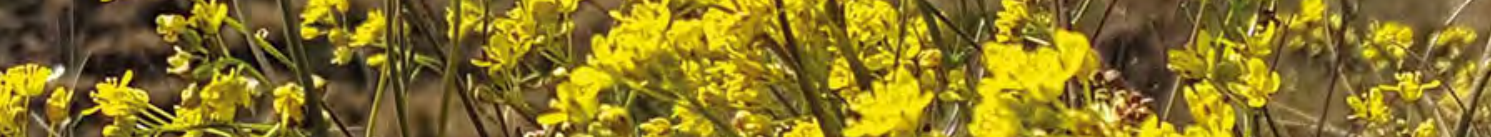

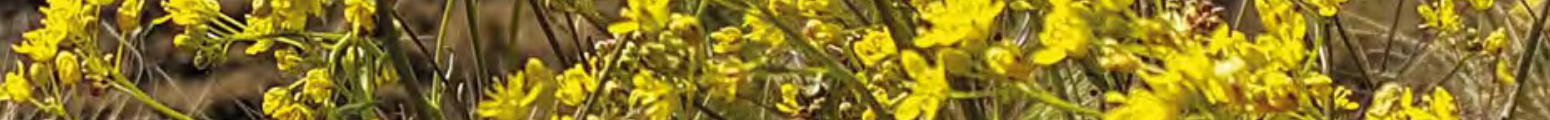

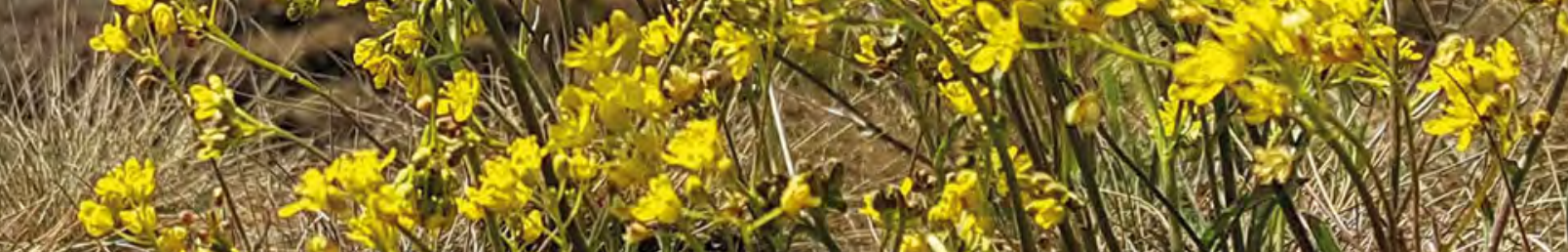

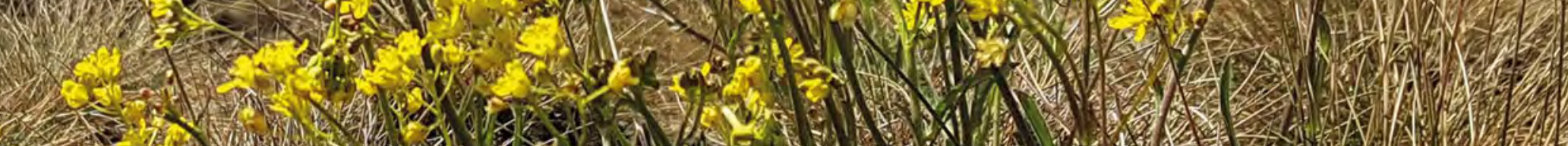
- 5 - er

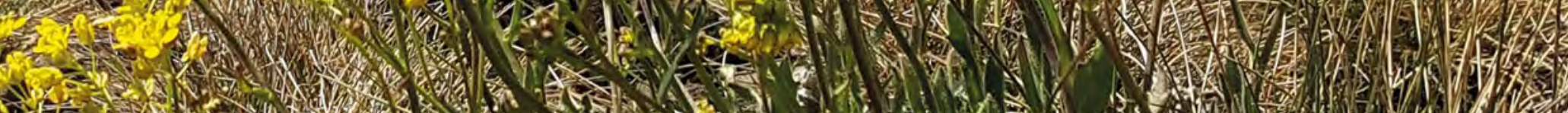
3.5. 2.

a.

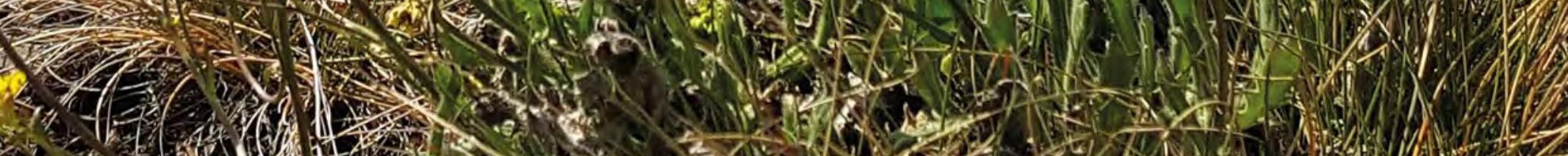

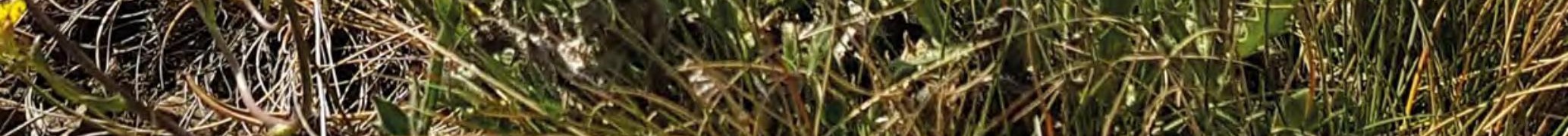

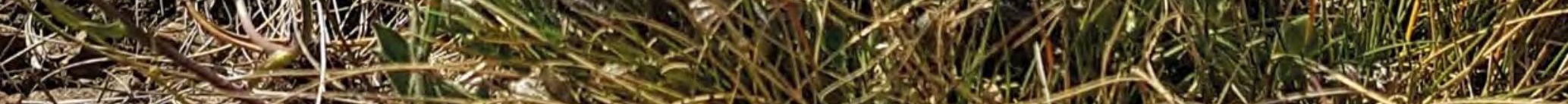

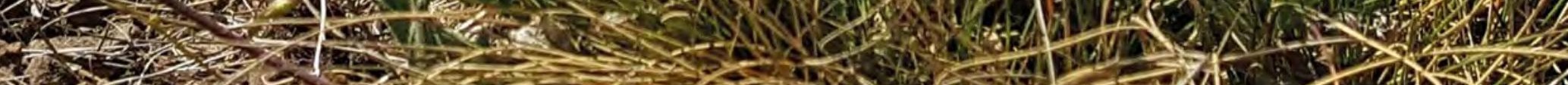

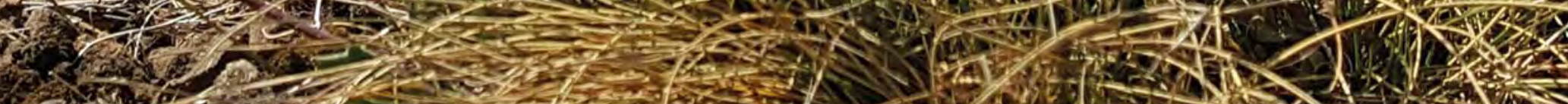
(1) 
Metallophytes have developed a predilection for e.g. zinc, lead, or nickel, and as a result of adaptation and evolution processes they have become perfectly adapted to life among toxins. The use of these properties is a challenge for scientists from various fields. One of the techniques gaining more and more supporters is phytoremediation (Old Greek: phytón - plant, Lating: remedium - remedy), i.e. technology using plants in the process of cleaning the environment: soil, groundwater and surface water, sewage sludge, and air. This method takes advantage of the physiological ability of certain plants to either exclude or accumulate contaminants present in the environment. Calamine grasslands (a mining term for oxidized zinc ores) are a testing ground for botanists, plant anatomists, embryologists, specialists dealing with plant physiology, and all those who focus their research on environmental protection. The researchers jokingly refer to themselves as a "heavy metal group."

In Europe, calamine grasslands are under special protection. In Poland, few of them have been left - in Lower Silesia (arsenic residues) and in the area of the Silesian-Cracow Upland (silver, lead, zinc). Old excavations, dumps, waste dumps left after the exploitation of various types of deposits, or remnants of metal smelting (there used to be over 100 smelters in the former Katowice Province) covered with grass, lichens, and flowering plants which do not mind metals, hide invaluable information for scientists.

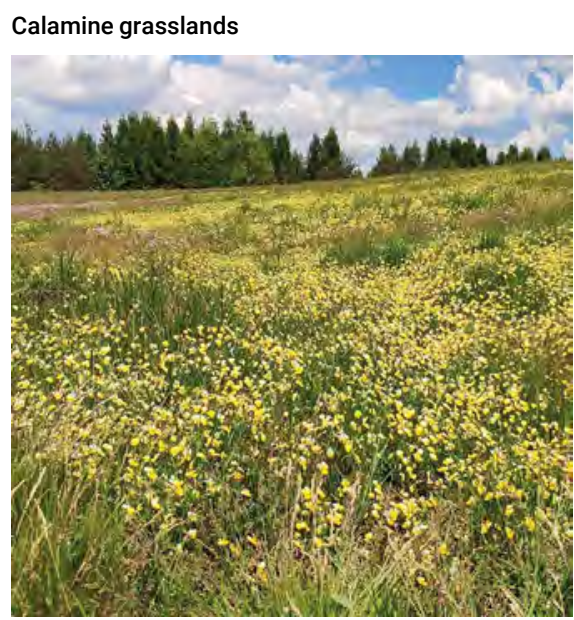

\section{SILESIAN "HEAVY METAL FANS"}

Dr. Monika Jędrzejczyk-Korycińska from the Institute of Biology, Biotechnology and Environmental Protection at the Faculty of Natural Sciences at the University of Silesia, has been coordinating the project co-financed by the European Union called Good practices for enhancing biodiversity and active protection of calamine grasslands in the Silesia-Cracow region; BioGalmans since 2018. Works are carried out on calamine grasslands on the washing tip of the Fryderyk mine in Tarnowskie Góry, in three areas in Jaworzno and on two grasslands within the region Natura 2000 in Bolesław: "Pleszczotka" and "Armeria". The project partners are the municipalities of Tarnowskie Góry and Jaworzno.

The researchers began their work with a huge cleanup. In order to protect the biodiversity of calamine grasslands and in accordance with the appropriate protective recommendations, the woody and shrub species that adversely affect the condition of the habitat had to be removed. Moreover, the fight against invasive and expansive species is underway, and the excess of organic matter has also been removed. Another extremely important element of the activities is the nature inventory, which includes species of vascular plants, mosses, lichens, as well as pollinators, ants, and spiders. The remaining part of the project has been taken over by the forces of nature, and their actions are being closely monitored. After just one year, the conservation efforts brought about surprising results.

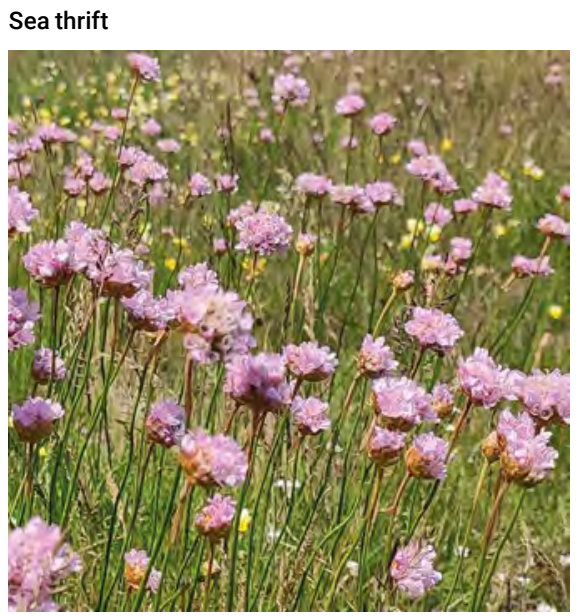

"The habitat was filled with desirable vegetation, rich and colorful," Dr. Monika Jędrzejczyk-Korycińska explains. "Carthusian carnations, woodruffs, anemones, and cloves have proliferated tremendously. There has also been a significant increase in turf species, heliophytes, and also those that are fantastic at coping with nutrient deficiencies. It did not take long for pollinators to arrive, either. If the number of flower species on calamine grasslands grows, the level of biodiversity increases as well, which is an unequivocal invitation for insects and other animals. In Tarnowskie Góry, we discovered the violet carpenter bee (Xylocopa violacea), a species of hymenoptera that was thought to be extinct in Poland. The surrounding grassland plant species turned out to be a bee's feast.

Some may be surprised by the cutting of a significant number of trees and shrubs. It turns out, however, that they do not cope very well with the excess of heavy metals in the soil and contract diseases, which is best evidenced by their appearance. They are deformed and withering, only at the tips they managed to cover themselves with green needles. In Tarnowskie Góry, on the top of the dolomite heap grew only pine trees, and under them hairy sedge (Carex hirta). Only two plant species could be found per one square meter, alongside with some common lichens and mosses. After the trees were removed, 20-30 species of vascular plants accompanied by lichens, bryophytes, and a variety of animal species were soon found on the same site. Therefore, from an ecological point of view and in order

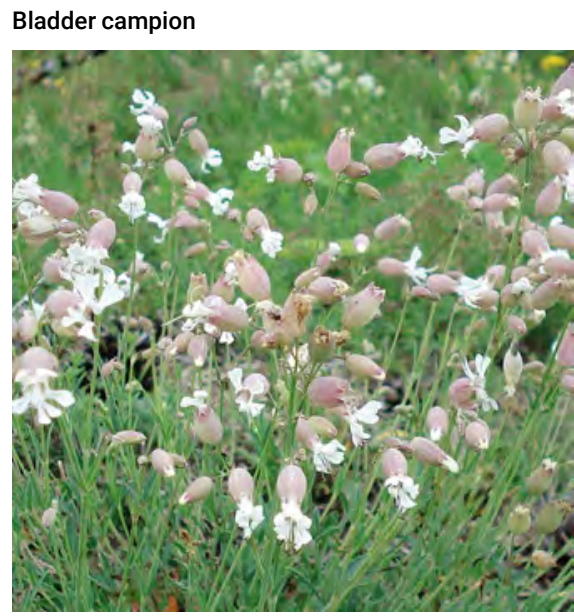


to preserve the biodiversity of calamine grasslands habitats (habitats under special supervision), the cutting of e.g. pine trees was a necessity.

\section{PHYTOSTABILIZATION AND PHYTOEXTRACTION}

The elimination of heavy metals or the reduction of their toxic impact on the environment are certainly possible with the use of physical or chemical methods. Unfortunately, these activities are very expensive and not entirely safe. According to Dr. Monika Jędrzejczyk-Korycińska, phytoremediation, i.e. environmental remediation with the use of plants, is the least harmful and, above all, the cheapest one. There are two main groups of processes that plants use. The first is phytostabilization. It involves the use of plant species that, with their roots firmly anchored in the ground, not only accumulate heavy metals in the soil, but most importantly, immobilize them so that they do not penetrate the parts above the ground. Through intensive growth, these species reduce the dusting of toxic metal waste on which they thrive.

The second process is phytoextraction, which uses plants that can extract very large amounts of metal from the soil and inject them into the parts above the ground, including the leaves. However, there is strict specialization, since some plants extract gold, others platinum, and still others extract lead, zinc, or copper. When a plant laden with metals dies, the metals remain in the environment but are bound in plant tissues and can be used. Phytomining is the method re-

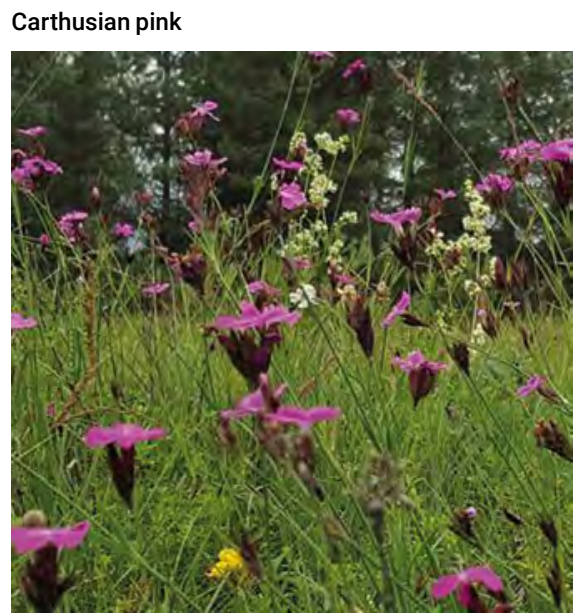

sorted to in order to recover metals from plants referred to as hyperaccumulators. The small-sized Pyrrophyta algae or Cardaminopsis cress are insufficient for industrial-scale recovery, but the mighty Reynoutria or goldenrods (Solidago) are more promising in this respect. Notwithstanding this, our scientist remains skeptical. Phytomining looks forward to plants with large masses, but such species are few in number and also often dangerous. The same applies to invasive species with a negative impact on biodiversity.

"Science must accept such challenges with due consideration. Plants which cannot be controlled must not be introduced into the environment. Recovering metals from the soil is an issue which definitely has to be addressed, but to maintain biodiversity at appropriate levels is more important for the stability of the entire ecosystem. It is necessary to stabilize areas contaminated with heavy metals by using native species that can be further utilized in the changing climate," the researcher concludes.

\section{METALLOPHYTES CAN SOON BECOME VERY USEFUL}

Plants that have grown fond of metals can cope with contaminated areas, are unafraid of mineral deficiencies, and have become perfectly adapted to physiological drought as well as to powerful insolation, i.e. intensive sunlight. Many grassland species, including grass, are now well accustomed to the difficulties they encountered, although they significantly differ from their brother or sister species in other regions of the country. The species popular in Poland, such as the sand rock-cress, sheep's fescue, bladder campion, or broad-leaved thyme, usually produce less matter on calamine grasslands; their leaves are small and have a xeromorphic structure, but they cope well with low substrate moisture, high sun exposure, poor nutrients, and high heavy metal concentrations. An interesting adaptation to such adverse conditions is e.g. an unusually elaborate root system coexisting with mycorrhizal fungi, since it allows them to increase their absorptive surface many times in order to collect water for the plant. In addition, species that grow on polluted areas are capable of flowering more than once, thanks to which they produce a huge number of seeds, a circumstance that gives them an advantage over other species.

These characteristics may soon prove to be extremely useful. The changing and increasingly warm climate as well as water scarcity plaguing all continents are a serious challenge to the environment, and some plant and animal species are threatened with extinction. Metallophytes preserved in calamine grasslands constitute an excellent gene pool that will be available once the ecosystem faces difficult times. Scientists are demanding the preservation of at least some of these valuable habitats, and their call is being implemented by European directives. Contaminated areas, which are usually mentioned in the context of neutralization and destruction, can be rehabilitated and used in a positive way," Dr. Monika Jedrzejczyk-Korycinska asserts.
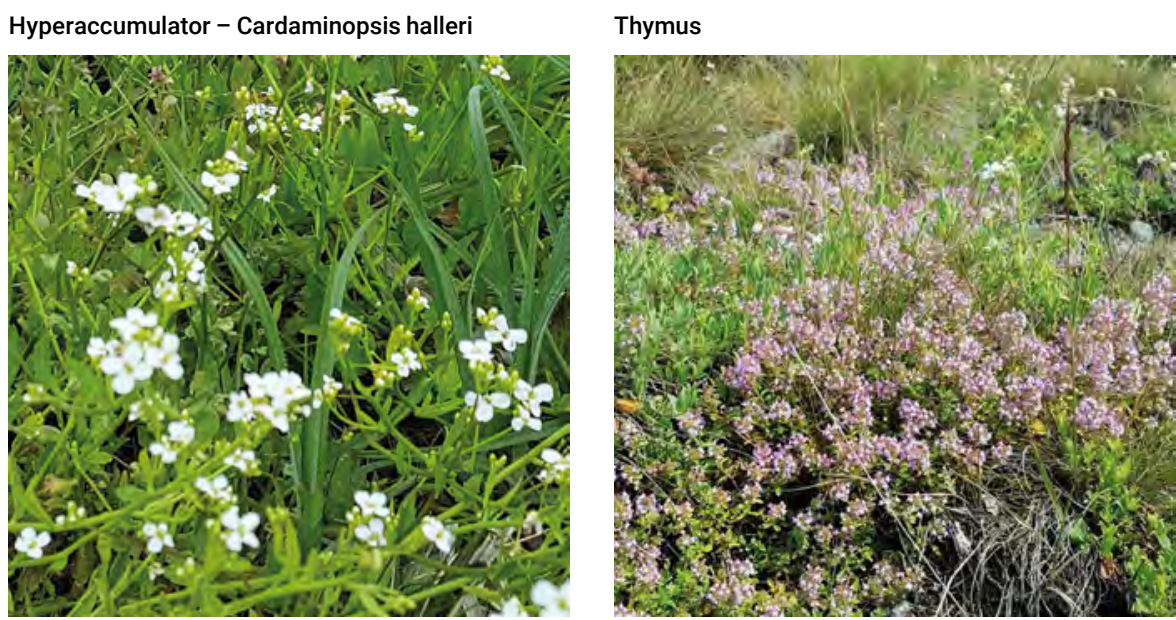